\title{
IDENTIFIKASI LANSEKAP ELEMEN SOFTSCAPE DAN HARDSCAPE PADA TAMAN BALEKAMBANG SOLO
}

\author{
Endang Wahyuni, Qomarun \\ Program Studi Teknik Arsitektur, Fakultas Teknik, Universitas Muhammadiyah Surakarta \\ Jl. A. Yani Tromol Pos 1 Pabelan Kartasura Sukoharjo 57102 Telp 0271-717417 \\ E-mail: ordinary_yuni@yahoo.com
}

\begin{abstract}
ABSTRAK
Penelitian ini bertujuan untuk mengidentifikasi ketepatan pemilihan dan penataan lansekap pada Taman Balekambang, Solo. Studi difokuskan pada elemen softscape dan hardscape di taman yang mempunyai luas sekitar 9,8 hektar itu. Aspek yang dikaji meliputi fungsi dan perannya dalam kaitannya dengan RTH (Ruang Terbuka Hijau). Penelitian menggunakan paradigma rasionalistik, dengan metode deskriptif-komparatif, yaitu dengan membandingkan antara kondisi faktual dengan regulasi atau referensi yang berkaitan. Selain narasi, pembahasan juga disajikan dalam bentuk tabulasi dan grafis. Hasil penelitian menunjukkan bahwa elemen softscape di Taman Balekambang secara garis besar mampu memenuhi kategori RTH. Namun demikian, untuk elemen hardscapenya, Taman Balekambang belum memenuhi standar kelengkapan yang dibutuhkan. Elemen softscape diketemukan kurang lebih 84 jenis tanaman, yang hampir semua sudah memenuhi syarat standar pemilihan tanaman. Keragaman karakter pohon ditemukan dalam bentuk tajuk indah (16,7\%), semak berdaun indah (16,7\%), pohon berbuah (35,7\%), pohon beraroma (2,4\%), pohon berbunga indah (5,6\%), pohon berdaun indah (38,1\%), peneduh (32,2\%), perdu bunga indah $(2,4 \%)$, rambat $(2,4 \%)$ dan semak berbunga indah (5,6\%). Selanjutnya, rekomendasi dari riset ini adalah pada upaya-upaya terkait pemeliharaan elemen softscape dan penyempurnaan elemen hardscape.
\end{abstract}

\section{Kata Kunci: lansekap, identifikasi, softscape, hardscape}

\section{PENDAHULUAN}

Taman Balekambang terletak di Kelurahan Manahan, Kecamatan Banjarsari, Solo. Awalnya taman ini bernama Partini Tuin dan Partinah Bosch, yang dibangun oleh KGPAA Mangkunegoro VII pada tanggal 26 Oktober 1921. Menurut Sajid (1984), namanama taman itu adalah berasal dari nama putri MN VII, yaitu GRAy Partini Husein Djayaningrat dan GRAy Partinah Sukanta. Namun lambat-laut taman ini dinamakan Balekambang, karena di dalam taman ini ada bangunan berupa bale atau gazebo berbentuk limasan yang berdiri di atas kolam, sehingga seolah-olah bale tersebut terapung di atas air kolam (kumambang).

Taman Balekambang dibangun dengan memadukan konsep Jawa dan Eropa (Sajid, 1984). Taman dibangun tidak hanya menciptakan unsur keindahan saja, tetapi juga ada unsur fungsi pada level kota. Partini Tuin atau Taman Air Partini berfungsi sebagai penampungan air untuk membersihkan atau menggelontor kotoran-kotoran sampah di dalam kota. Selain itu, taman ini juga sering digunakan untuk bermain perahu. Sementara itu, Partinah Bosch atau Hutan Partinah disengaja untuk fungsi hutan kota. Taman ini berisi koleksi tanaman langka, seperti kenari, beringin putih, beringin sungsang, apel coklat, dan sebagainya. Jadi, berbeda dengan Partini Tuin yang digunakan untuk utilitas kota, maka Partinah Bosch berfungsi sebagai resapan dan paru-paru kota (Sajid, 1984). Selanjutnya, riset ini akan mengkaji sejauh manakah ketepatan penataan elemen lansekap (softscape dan hardscape) terkait RTH (Ruang Terbuka Hijau) kota. Jadi, tujuan penelitian ini adalah untuk mengidentifikasi ketepatan penggunaan elemen hardscape maupun softscape terhadap aspek-aspek yang berkaitan dengan RTH. Selanjutnya, untuk memperlihatkan lebih jelas tentang kondisi Taman Balekambang Solo saat ini, maka ditampikkan peta lokasi, gambar situasi dan foto-foto lapangan sebagai berikut: 


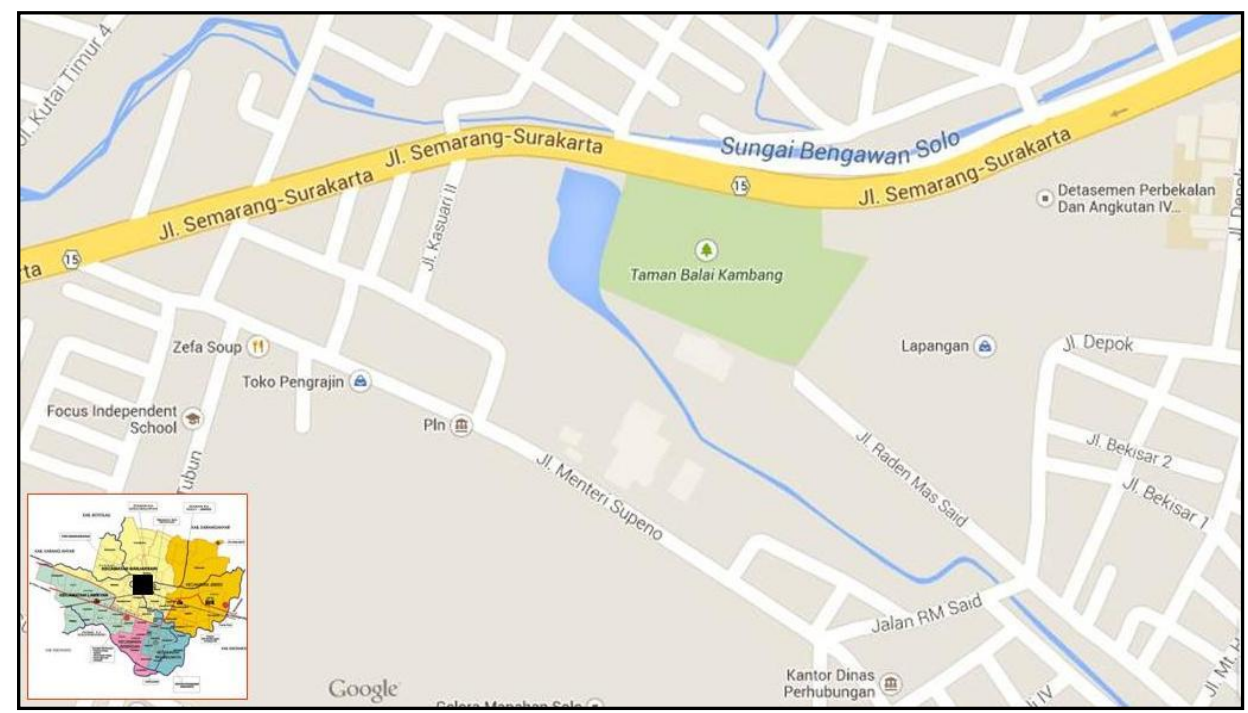

Gambar 1. Peta Lokasi Taman Balekambang Solo

(Sumber: www.wikimapia.com, 2014 dan www.surakarta.go.id, 2014)

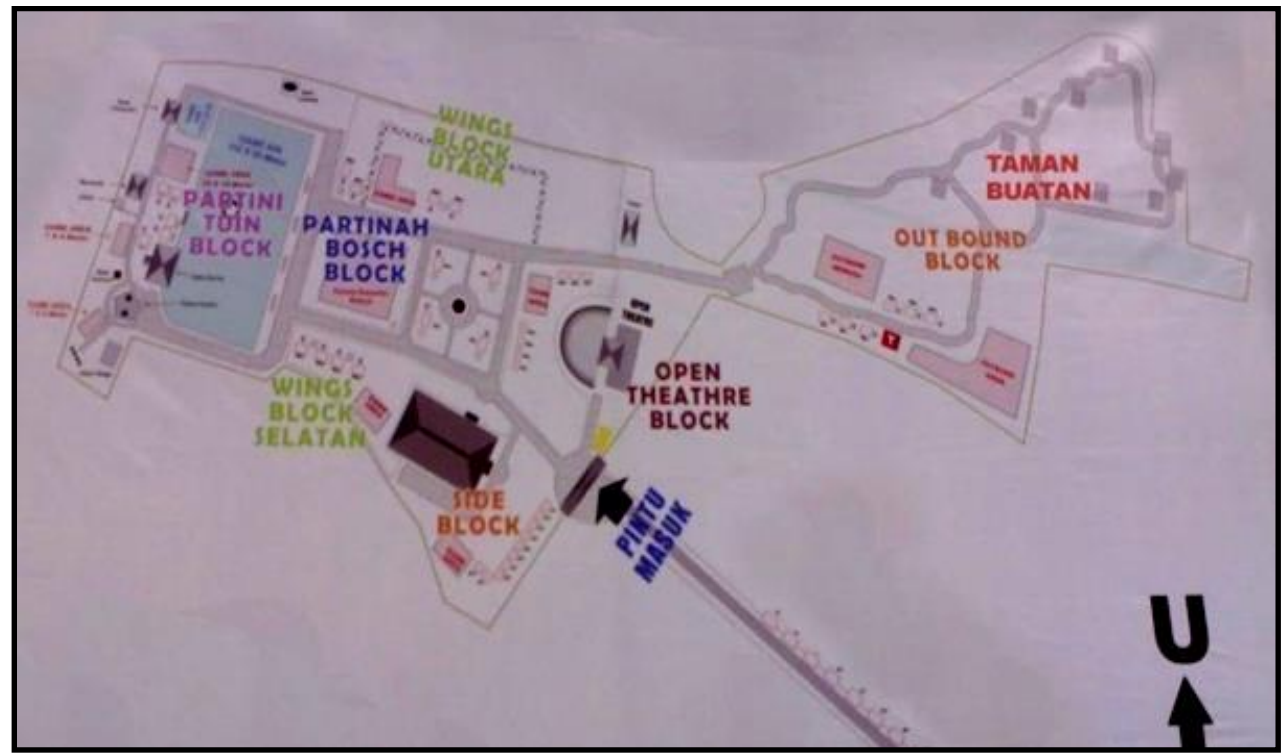

Gambar 2. Situasi Taman Balekambang

(Sumber, Survei, 2014)
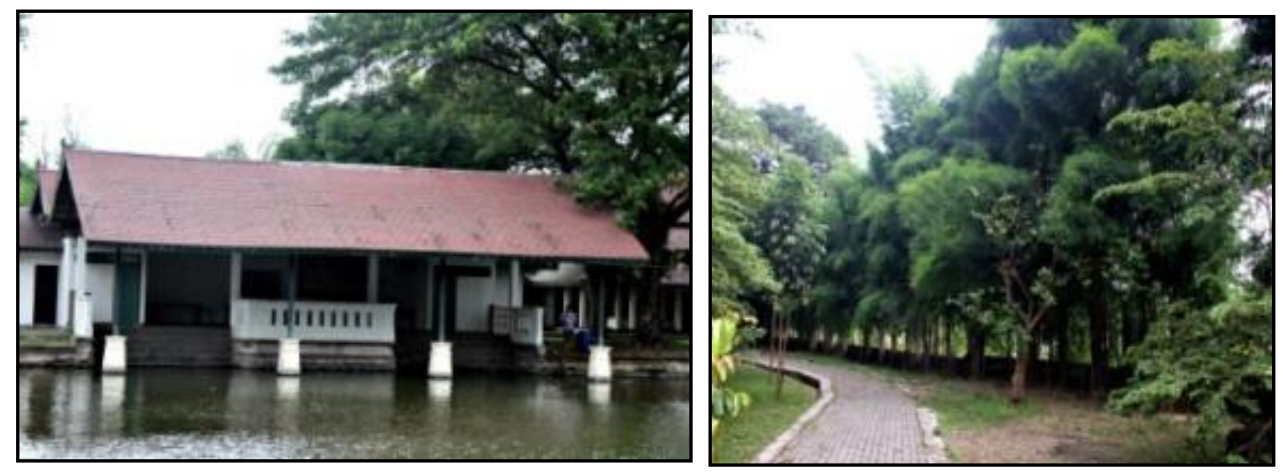

Gambar 3. Kondisi Fasad Bangunan Balekambang (foto kiri) dan Elemen Softscape dan Hardscape (foto kanan)

(Sumber: Survei, 2014) 


\section{TINJAUAN PUSTAKA Desain Taman}

Pada dasarnya, desain taman (lansekap), seperti juga pada desain bangunan, merupakan pengaturan dan ekspresi dari elemen-elemen desain itu sendiri. Elemen desain itu terdiri dari titik, garis, bentuk, pola, warna, tekstur, bunyi, aroma dan gerak. Karakter atau sifat yang melekat pada elemen taman ditata berdasarkan prinsip-prinsip desain. Menurut Ashihara (1996), dalam perancangan taman perlu dilakukan pemilihan dan penataan secara detail elemenelemennya, agar taman dapat fungsional dan estetis. Elemen taman dapat diklasifikasikan menjadi 3 kategori, yaitu: (1) berdasarkan jenis dasar elemen; (2) berdasarkan kesan yang ditimbulkan; dan (3) berdasarkan kemungkinan perubahan. Untuk kategori pertama (berdasar jenis), elemen taman dibagi menjadi dua macam, yaitu elemen alami (ciptaan Allah) dan elemen non-alami (buatan manusia). Sementara itu, untuk kategori kedua (berdasar kesan), elemen taman dibagi menjadi dua macam, yaitu elemen lunak (soft material), seperti tanaman, air, satwa dan elemen keras (hard material), seperti paving, pagar, patung, pergola, bangku taman, kolam dan lampu taman.

Selanjutnya, berdasarkan kemungkinan perubahan, maka taman dibagi menjadi dua macam, yaitu elemen mayor (elemen yang sulit diubah), seperti sungai, gunung, pantai, hujan, kabut, suhu, kelembaban udara, radiasi matahari, angin, petir, dan elemen minor (elemen yang dapat diubah), seperti sungai kecil, bukit kecil, tanaman, serta elemen buatarn manusia.

Prinsip-prinsip dasar desain tentang pembuatan taman terdiri dari 4 macam (Arifin, 2006), yaitu: (1) tema; (2) gradasi; (3) kontras; dan (4) keseimbangan. Prinsip tema bertujuan untuk membentuk kesan menyatu (unity). Prinsip tema harus mampu memunculkan karakter, identitas atau kesan utama. Melalui unity, karakter taman dapat terlihat dengan jelas, misalkan memiliki karakter sebagai taman bermain, taman rumah, taman formal dan taman tropis. Sementara itu, prinsip gradasi bertujuan untuk menimbulkan kesan gerak, sehingga terkesan dinamis dan berirama.

Permainan variasi dan repetisi akan mencegah kemonotonan. Untuk gradasi warna, sebagai contoh dapat dilakukan melalui pemilihan warna hijau menjadi hijau tua atau ke hijau muda. Sementara itu, untuk gradasi bentuk, dapat dilakukan dengan bulat kemudian diolah menjadi berbagai variasi bulat, misalkan berdasarkan ukuran (kecilbesar), berdasarkan tekstur (halus-kasar) dan sebagainya. Sementara itu, prinsip kontras bertujuan untuk menarik perhatian. Pemberian kontras ini akan memberikan kesan kejutan ataupun klimaks. Teknik kontras, antara lain dapat dibuat dengan menerapkan warna yang menyolok, bentuk individual yang menarik dan elemen yang unik. Selanjutnya, prinsip keseimbangan bertujuan agar taman terkesan harmonis.

Selanjutnya, untuk memperjelas prinsipprinsip desain tersebut di atas, maka disajikan tabel prinsip desain sebagai berikut:

Tabel 1. Matrik Prinsip Desain Lansekap

\begin{tabular}{|c|c|c|c|c|}
\hline $\begin{array}{c}\text { Elemen } \\
\text { Desain }\end{array}$ & \multicolumn{4}{|c|}{ Prinsip Desain } \\
\cline { 2 - 5 } Garis & $\begin{array}{c}\text { Teng- } \\
\text { kung }\end{array}$ & $\begin{array}{c}\text { Gradasi } \\
\text { Vengasiasi } \\
\text { Lengkung }\end{array}$ & $\begin{array}{c}\text { Lurus, } \\
\text { Geometrik }\end{array}$ & $\begin{array}{c}\text { Balance, } \\
\text { Proporsio } \\
\text { nal }\end{array}$ \\
\hline Bentuk & Bulat & $\begin{array}{c}\text { Bulat Kecil- } \\
\text { Besar }\end{array}$ & $\begin{array}{c}\text { Segi-4, } \\
\text { Geometrik }\end{array}$ & $\begin{array}{c}\text { Balance, } \\
\text { Proporsio } \\
\text { nal }\end{array}$ \\
\hline Warna & Hijau & $\begin{array}{c}\text { Gradasi } \\
\text { Hijau }\end{array}$ & $\begin{array}{c}\text { Kuning, } \\
\text { Merah }\end{array}$ & $\begin{array}{c}\text { Balance, } \\
\text { Proporsio } \\
\text { nal }\end{array}$ \\
\hline Tekstur & Halus & $\begin{array}{c}\text { Sdang- } \\
\text { Halus }\end{array}$ & Kasar & $\begin{array}{c}\text { Balance, } \\
\text { Proporsio } \\
\text { nal }\end{array}$ \\
\hline
\end{tabular}

(Sumber: Arifin, 2006)

\section{Elemen Lansekap}

Elemen-elemen pendukung lansekap dapat dibedakan atas dua macam, yaitu (Handayani, 2009): elemen lunak (softscape) dan elemen keras (hardscape). Elemen lunak adalah elemen pendukung yang biasanya merupakan vegetasi, seperti pepohonan, perdu dan rerumputan. Penggunaan tanaman sangat berperan terhadap hasil penataan suatu lansekap. Elemen tanaman memiliki beberapa sifat khas yang membedakannya dengan berbagai elemen lainnya. Karakteristik yang paling penting dan menonjol adalah bahwa tanaman merupakan elemen yang hidup dan tumbuh. Dengan sifat khas demikian maka ada beberapa hal yang harus diperhatikan. Pertama, tanaman merupakan elemen yang dinamis, setiap saat berubah, baik itu ukuran, tekstur, kelebatan daun maupun karakter keseluruhan sesuai dengan 
sifat pertumbuhannya. Kedua, kualitas dinamis tadi mempunyai implikasi terhadap penggunaan tanaman dalam penataan lansekap. Karakteristik tanaman menampilkan ciri dan bentuk tanaman yang terdiri dari: ukuran, bentuk, warna dan tekstur tanaman. Masing-masing ciri tersebut berpengaruh langsung terhadap hasil penataan lansekap.

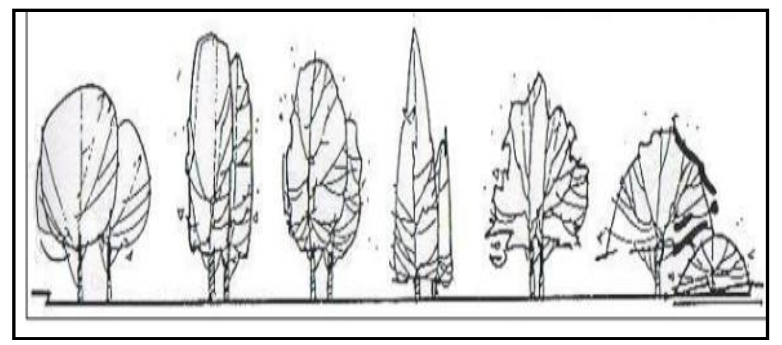

Gambar 4. Keragaman Bentuk Tanaman (Sumber: Handayani, 2009)

Setiap peletakan unsur tanaman dalam lansekap harus memiliki tujuan dan fungsi yang jelas. Tanaman dalam penataan lansekap memiliki tiga fungsi utama: (1) fungsi arsitektural, yaitu pemanfaatan tanaman untuk membentuk bidang-bidang tegak terutama dalam membentuk ruang; (2) fungsi lingkungan, yaitu fungsi tanaman yang lebih ditekankan untuk menciptakan kenyamanan dan keamanan dari faktor-faktor gangguan lingkungan, seperti polusi, erosi dan lain-lain; dan (3) fungsi estetis tanaman, yaitu untuk memberikan nilai-nilai keindahan dalam mendukung kedua fungsi di atas. Sementara itu, elemen keras (hardscape) merupakan unsur tidak hidup dalam lansekap dan berfungsi sebagai unsur pendukung untuk meningkatkan kualitas lansekap tersebut. Elemen keras dapat berupa lampu-lampu taman, bangku dan meja taman, gazebo, kolam, bebatuan, kerikil dan lain-lain.

Tabel 2. Jenis dan Ukuran Tanaman

\begin{tabular}{|l|l|l|}
\hline $\begin{array}{l}\text { JENIS/UKURAN } \\
\text { TANAMAN }\end{array}$ & \multicolumn{1}{|c|}{ KARAKTERISTIK DAN PERANAN DALAM TAMAN } & CONTOH TANAMAN \\
\hline $\begin{array}{l}\text { Pohon Kecil } \\
3-6 \mathrm{~m} .\end{array}$ & $\begin{array}{l}\text { Kanopi membentuk ruang akrab. Cocok pada } \\
\text { halaman yang kecil. Menjadi penarik visual bila } \\
\text { digabung dengan tanaman rendah }\end{array}$ & $\begin{array}{l}\text { Belimbing, Kemboja, } \\
\text { Cemara kipas }\end{array}$ \\
\hline $\begin{array}{l}\text { Pohon } \\
\text { Sedang } \\
9-12 \mathrm{~m} .\end{array}$ & Tidak cocok untuk halaman yang kecil & $\begin{array}{l}\text { Nangka, Kisabun, } \\
\text { Jambu air }\end{array}$ \\
\hline $\begin{array}{l}\text { Pohon Besar } \\
>12 \mathrm{M} .\end{array}$ & Penarik visual & $\begin{array}{l}\text { Mahoni, Damar, } \\
\text { Kihujan }\end{array}$ \\
\hline $\begin{array}{l}\text { Semak/Perdu } \\
\text { tinggi } \\
3-4,5 \mathrm{~m} .\end{array}$ & $\begin{array}{l}\text { Berperan sebagai dinding. Digunakan sebagai } \\
\text { sekat dan pembentuk ruang yang bersifat privat } \\
\text { atau sebagai latar belakang netral bagi patung } \\
\text { atau tanaman berbunga }\end{array}$ & $\begin{array}{l}\text { Kol merak, Kol banda, } \\
\text { Nusa indah }\end{array}$ \\
\hline
\end{tabular}

\begin{tabular}{|l|l|l|}
\hline Semak & Digunakan untuk pembatas ruang, sebagai unsur & Puring, \\
Sedang dan & peralihan komposisi dari semak tinggi ke semak & Kembang sepatu, \\
Redah & rendah. & Diefen bahia. \\
$0,3-2 \mathrm{~m}$. & Sebaiknya ditanam dalam kelompok besar & \\
\hline $\begin{array}{l}\text { Pohon } \\
\text { Ornamental }\end{array}$ & Tidak cocok digabung dalam komposisi. & Cemara norfolk. \\
& Sangat cocok dipasang dekat pintu gerbang & Tanaman yang \\
& masuk karena menarik perhatian & berubah karena alam \\
\hline $\begin{array}{l}\text { Penutup } \\
\text { tanah }\end{array}$ & Membentuk pola bidang alas. & Lantana, Lili paris, \\
$15-30 \mathrm{~cm}$ & Pembatas antara rumput dan perkerasan. & Portulaka. \\
& Dapat menghubunkan unsur unsur dalam & \\
& komposisi. & \\
& Menutuptanahyang tidaksesuaidengan rumput. & \\
\hline
\end{tabular}

(Sumber: Handayani, 2009)

\section{Kriteria Tanaman RTH}

Ruang Terbuka Hijau (RTH) adalah ruang yang berisi tanaman berkayu, harus dapat menyerap air, berbentuk memanjang atau mengelompok, berguna untuk aspek ekologis, sosial, arsitektural maupun ekonomis bagi masyarakatnya (UU No. 63/2002). Secara fisik, RTH terbagi dalam dua kategori, yaitu RTH alami dan non-alami, sedangkan secara kepemilikan, RTH terbagi menjadi RTH publik dan privat. Sementara itu, secara fungsional, RTH terbagi menjadi 4 kategori, yaitu: ekonomis, ekologis, sosial dan arsitektural; sedangkan secara struktural, RTH terbagi menjadi 2 macam, yaitu pola planologis dan pola ekologis (UU No. 63/2002). Berdasarkan karakteristik pohon dan tipe penggunaannya, maka jenis pohon $\mathrm{RTH}$ dapat dijelaskan melalui tabel sebagai berikut:

Tabel 3. Jenis Pohon RTH dan Karakteristiknya

\begin{tabular}{|c|c|c|}
\hline $\begin{array}{l}\text { Bentuk } \\
\text { Tanaman } \\
\text { dan } \\
\text { Contoh }\end{array}$ & Karakteristik & $\begin{array}{l}\text { Penggunaan } \\
\text { dalam Taman }\end{array}$ \\
\hline $\begin{array}{l}\text { Melebar/ } \\
\text { Spreading } \\
\text { Flamboyan } \\
\text { Sengon } \\
\text { Hujan Mas }\end{array}$ & $\begin{array}{l}\text { Lebar tajuk kira-kira } \\
\text { sama dengan } \\
\text { tingginya. } \\
\text { Menampilkan kesan } \\
\text { luas dan melebar. } \\
\text { Kontras terhadap } \\
\text { bentuk yang tinggi } \\
\text { ramping. Menjadi } \\
\text { penghubung dengan } \\
\text { bentuk lain dalam } \\
\text { suatu komposisi. }\end{array}$ & $\begin{array}{l}\text { Cocok ditempatkan } \\
\text { pada permukaan } \\
\text { tanah datar. } \\
\text { Dipergunakan untuk } \\
\text { meneruskan garis } \\
\text { bangunan. } \\
\text { Untuk menyatukan } \\
\text { bangunan dengan } \\
\text { tapak sekitarnya. }\end{array}$ \\
\hline $\begin{array}{l}\text { Bulat } \\
\text { Kisabun } \\
\text { Nangka } \\
\text { Kasia } \\
\text { Singapur }\end{array}$ & $\begin{array}{l}\text { Merupakan bentuk } \\
\text { yang relative banyak } \\
\text { ditemui. Bersifat } \\
\text { netral dalam suatu } \\
\text { komposisi. Mudah } \\
\text { menyatukan dalam } \\
\text { komposisi. }\end{array}$ & $\begin{array}{l}\text { Cocok pada tanah } \\
\text { yang datar. } \\
\text { Kurang cocok } \\
\text { digunakan sebagai } \\
\text { pohon pengarah. } \\
\text { Digunakan untuk } \\
\text { pelembut pada } \\
\text { bentuk yang } \\
\text { mencolok. }\end{array}$ \\
\hline $\begin{array}{l}\text { Tinggi } \\
\text { Ramping }\end{array}$ & $\begin{array}{l}\text { Menarik perhatian ke } \\
\text { atas. Menghasilkan } \\
\text { ruang yang tinggi } \\
\text { vertikal. Kontras }\end{array}$ & $\begin{array}{l}\text { Di gunakan dalam } \\
\text { jumlah terbatas } \\
\text { pada titik-titik } \\
\text { tertentu saja. }\end{array}$ \\
\hline
\end{tabular}




\begin{tabular}{|l|l|l|}
\hline $\begin{array}{l}\text { Cemara Lilin } \\
\text { Tiang }\end{array}$ & $\begin{array}{l}\text { jika di komposisikan } \\
\text { dengan bentuk bulat } \\
\text { atau menyebar. } \\
\text { Berperan sebagai } \\
\text { aksen }\end{array}$ & $\begin{array}{l}\text { Tidak di anjurkan } \\
\text { diletakkan } \\
\text { menyebar karena } \\
\text { memecah } \\
\text { perhatian. } \\
\text { Sebagai pohon } \\
\text { pengarah. }\end{array}$ \\
\hline Columnar & $\begin{array}{l}\text { Memiliki karakter } \\
\text { sama dengan bentuk } \\
\text { tinggi ramping }\end{array}$ & $\begin{array}{l}\text { Dapat di } \\
\text { manfaatkan seperti } \\
\text { pada pohon bentuk } \\
\text { tinggi ramping. }\end{array}$ \\
Puspa & $\begin{array}{l}\text { Merupakan bentuk } \\
\text { yang relative banyak } \\
\text { di temui. Bersifat } \\
\text { netral dalam suatu } \\
\text { komposisi. Mudah } \\
\text { menyatukan dalam } \\
\text { suatu komposisi. }\end{array}$ & $\begin{array}{l}\text { Di gunakan sebagai } \\
\text { aksen visual } \\
\text { terutama jika di tata } \\
\text { dengan bentuk } \\
\text { yang bulat rendah. } \\
\text { Cocok digunakan } \\
\text { pada pola-pola } \\
\text { geometris atau } \\
\text { formal. }\end{array}$ \\
Kemara
\end{tabular}

(Sumber: Handayani, 2009)

Secara umum, kriteria pemilihan vegetasi untuk RTH (Ruang Terbuka Hijau) adalah sebagai berikut (DPU, 2008): (1) tidak beracun, tidak berduri, dahan tidak mudah patah, perakaran tidak mengganggu pondasi; (2) tajuk cukup rindang dan kompak, tetapi tidak terlalu gelap; (3) ketinggian tanaman bervariasi, warna hijau dengan variasi warna lain seimbang; (4) perawakan dan bentuk tajuk cukup indah; (5) kecepatan tumbuh sedang; (6) berupa habitat tanaman lokal dan tanaman budidaya; (7) jenis tanaman tahunan atau musiman; (8) jarak tanam setengah rapat sehingga menghasilkan keteduhan yang optimal; (9) tahan terhadap hama penyakit tanaman; (10) mampu menjerap dan menyerap cemaran udara; dan (11) sedapat mungkin merupakan tanaman yang mengundang burung. Selanjutnya, berikut ini diuraikan kajian elemen softscape dan hardscape terkait RTH:

\section{Elemen Softscape}

Menurut Hakim (1991), elemen softscape tergantung pada aspek arsitektural atau artistik visual, yaitu: (a) pengontrol pemandangan; (b) penghalang secara fisik; (c) pengontrol iklim; (d) pelindung dari erosi; dan (e) pemberi nilai estetis. Sementara itu, ditinjau dari tajuk, bentuk massa dan struktur tanaman (DPU, 2008), maka elemen softscape adalah:

a. Tajuk merupakan keseluruhan bentuk dan kelebaran maksimal tertentu dari ranting dan daun suatu tanaman.

b. Struktur Tanaman ialah bentuk tanaman yang terlihat secara keseluruhan.

Selanjutnya, menurut Indrawati (2007), maka elemen softscape terdiri atas:

a. Tanaman pohon berjenis tanaman berkayu yang biasanya mempunyai batang tunggal dan dicirikan dengan pertumbuhan yang sangat tinggi mencapai lebih dari $8 \mathrm{~m}$.

b. Tanaman perdu adalah tanaman berkayu yang pendek dengan batang yang cukup kaku dan kuat untuk menopang bagianbagian tanaman. Golongan perdu biasanya dibagi menjadi tiga, yaitu perdu rendah, perdu sedang, dan perdu tinggi.

c. Tanaman semak (shrubs) dicirikan dengan batang yang berukuran sama dan sederajat. Pada umumnya tanaman ini mempunyai ketinggian di bawah $8 \mathrm{~m}$.

d. Tanaman merambat (liana) dicirikan dengan batang yang tidak berkayu dan tidak cukup kuat untuk menopang bagian tanaman lainnya.

e. Tanaman dengan sedikit jaringan sekunder atau tidak berkayu, tetapi dapat berdiri tegak, seperti Herba, Terna, Bryoids dan Sukulen. Ukurannya dibagi berdasarkan tingginya.

Menurut DPU (2008), fungsi tanaman dalam pembentuk dan pengisi ruang meliputi:

a. Tanaman pelantai (ground cover), tanaman yang membentuk kesan lantai, digunakan sebagai penutup tanah di taman. Tanaman ini tingginya sekitar mata kaki.

b. Tanaman pedinding, adalah tanaman yang membentuk kesan dinding, dibagi menjadi:

(1) Tanaman yang membentuk dinding rendah, yaitu tanaman setinggi mata kaki sampai setinggi lutut.

(2) Tanaman yang membentuk dinding sedang, yaitu tanaman yang setinggi lutut sampai setinggi badan seperti semak yang sudah besar dan perdu. 
(3) Tanaman yang membentuk dinding tinggi, yaitu tanaman yang setinggi badan sampai beberapa meter.

(4) Tanaman pembatas, pengarah dan pembentuk pandangan adalah jenis tanaman berbentuk pohon atau perdu yang berfungsi sebagai pembatas pemandangan yang kurang baik, pengarah gerakan bagi pemakai jalan menuju ke suatu tujuan tertentu.

(5) Tanaman pengarah, penahan dan pemecah angin adalah jenis tanaman yang berfungsi sebagai pengarah, penahan dan pemecah angin, dapat berbentuk pohon atau perdu

c. Tanaman pengatap atau peneduh, adalah jenis tanaman berbentuk pohon dengan percabangan yang tingginya lebih dari 2 meter.

d. Tanaman pengisi ruang, adalah tanaman yang mempunyai warna menarik pada bunga, daun, kulit batang atau dahan, serta yang bertajuk indah.

\section{Elemen Hardscape}

Elemen hardscape terdiri dari 10 macam kriteria, yaitu: batuan, gazebo, kolam, tebing, jalan, perkerasan, lampu, pagar, pergola dan bangunan. Batuan tidak baik bila diletakkan di tengah taman, sebaiknya di letakkan agak menepi atau pada salah satu sudut taman. Gazebo adalah bangunan peneduh atau rumah kecil di taman yang berfungsi sebagai tempat beristirahat menikmati taman. Kolam sering dipadukan dengan batuan tebing dengan permainan air yang menambah kesan dinamis. Kolam akan tampil hidup bila ada permainan air di dalamnya. Tebing dibuat untuk memberikan kesan alami, tebing dibuat dengan maksud untuk menyembunyikan tembok pembatas dinding yang licin massif, agar tidak menyilaukan pada saat matahari bersinar sepanjang siang. Jalan setapak dibuat agar dalam pemeliharaan taman tidak merusak rumput dan tanaman, selain itu jalan setapak berfungsi sebagai unsur variasi elemen penunjang taman. Perkerasan bertujuan untuk para pejalan kaki (pedestrian) atau sebagai pembatas. Lampu taman berfungsi penerang taman dan sebagai nilai estetik. Sementara itu, pagar dituntut mendekati keserasian, minimal mengikuti kriteria berikut: a. Ketinggian maksimal 1,2 $\mathrm{m}$ bidang tembus pandang sebesar $60 \%$, bidang masif setinggi $0,5 \mathrm{~m}$ dari permukaan halaman.

b. Pemerataan ketinggian untuk mencapai pola yang ritmis.

c. Bidang tembus pandang sebagai aplikasi terhadap control lingkungan, ketertiban penghuni dan sifat keterbukaan, keramahan terhadap lingkungan.

Selanjutnya, terkait pergola, yang berupa rangka-rangka yang dibuat untuk menyangga dan merambatkan tanman, harus kuat dan rapi. Sementara itu, untuk bangunan atau gedung di taman, maka yang perlu dipahami adalah sebagai berikut:

a. Antara bangunan dan ruang-luar-nya harus merupakan satu kesatuan penampilan.

b. Pemahaman nilai-nilai bentuk dan garis pada bangunan untuk menyelaraskannya dengan penampilan lansekap.

c. Pemahaman bagian-bagian bangunan dalam hubungannya dengan lansekap, karena lansekap memang melengkapi fungsi dan estetika bangunan sehingga bagus dipandang baik dari luar maupun dari dalam bangunan.

d. Memanfaatkan bagian bangunan dalam penampilan lansekap sehingga benarbenar tidak ada pemisahan antara bangunan dan ruang luar.

Berdasarkan kajian pustaka di atas, maka berikut ini ditampilkan tabel tolok ukur RTH pada elemen softscape dan hardscape: 
Tabel 4. Tolok Ukur RTH Softscape dan Hardscape

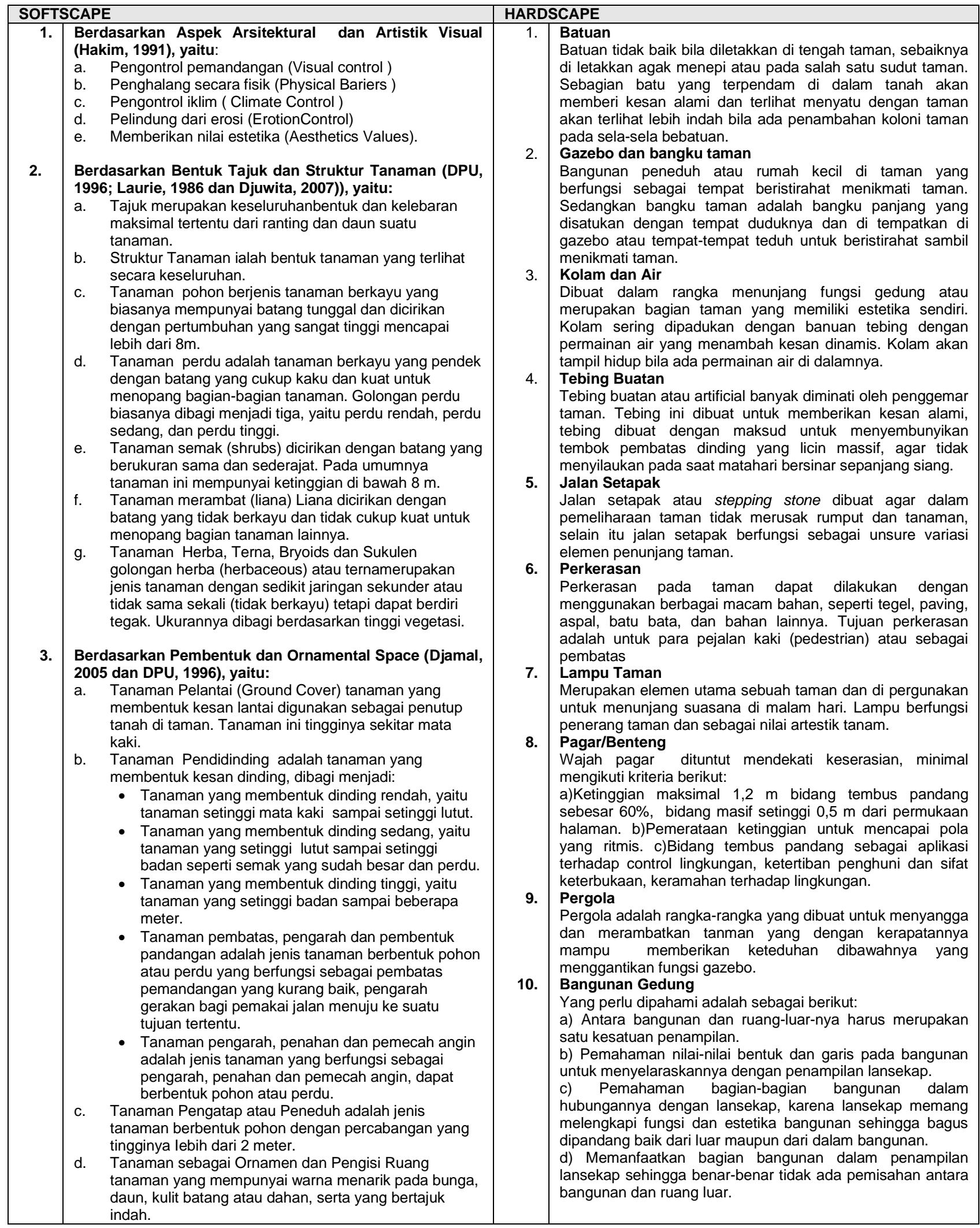




\section{METODE PENELITIAN}

Secara umum, metode penelitian yang digunakan adalah rasionalistik-kualitatif. Analisis dilakukan dengan menggunakan metode deskritif-komparatif, yaitu menggambarkan kondisi faktual dengan kondisi regulasi atau referensi yang terkait. Selain narasi, pembahasan disajikan dalam bentuk tabulasi dan grafis.. Studi dilakukan terfokus pada penataan lansekap, yaitu penggunaan elemen softscape dan elemen hardscape pada Taman Balekambang di Surakarta, yang berperan sebagai RTH (Ruang Terbuka Hijau). Untuk mengetahui serta mengidentifikasi penggunaan elemen softscape dan elemen hardscape pada
Taman Balekambang di Surakarta sebagai RTH dilakukan melalui data primer dan sekunder. Data primer diperoleh secara observasi langsung di lapangan dengan melaksanakan survei dan wawancara di Taman Balekambang, sedangkan data sekunder diperoleh melalui berbagai pustaka, baik pustaka manual maupun digital.

\section{HASIL PENELITIAN DAN PEMBAHASAN}

Berdasarkan temuan lapangan dan analisisnya, maka kondisi elemen softscape dan hardscape di Taman Balekambang Solo dan analisis ketepatannya dapat ditampilkan melalui tabel-tabel berikut ini:

Tabel 5. Data Softscape Taman Balekambang, 2014

\begin{tabular}{|c|c|c|c|c|c|}
\hline No. & Nama Pohon & Jumlah & No. & Nama Pohon & Jumlah \\
\hline 1. & Akasia & 7 & 45. & Mahoni & 70 \\
\hline 2. & Andong merah & 2 & 46. & Malaba & 14 \\
\hline 3. & Apel bludru & 12 & 47. & Mangga & 39 \\
\hline 4. & Ara & 1 & 48. & Melati air & 7 \\
\hline 5. & Asem & 2 & 49. & Mengkudu & 2 \\
\hline 6. & Bamboo & 837 & 50. & Mojo beruk & 2 \\
\hline 7. & Batavia & 3 & 51. & Munggur & 13 \\
\hline 8. & Blimbing bintang & 2 & 52. & Palem & 61 \\
\hline 9. & Blimbing wuluh & 2 & 53. & Papaya & 0 \\
\hline 10. & Beringin & 30 & 54. & Petai cina & 51 \\
\hline 11. & Beringtonia & 6 & 55. & Pilo jari / pilo dendrum & 35 \\
\hline 12. & Bintaro & 3 & 56. & Pinus & 2 \\
\hline 13. & Bogenvil & 13 & 57. & Pisang & 94 \\
\hline 14. & Buah naga & 3 & 58. & Pohon gayem / solok & 16 \\
\hline 15. & Bunga eurphorbia & 9 & 59. & Pohon kelengkeng & 4 \\
\hline 16. & Cemara norfork & 5 & 60. & Pohon nangka & 5 \\
\hline 17. & Cemara gunung & 18 & 61. & Pohon perdamaian & 7 \\
\hline 18. & Cemara lilin & 27 & 62. & Pohon tanjung & 40 \\
\hline 19. & Cemara udang & 1 & 63. & Puring & 25 \\
\hline 20. & Cokelat & 1 & 64. & Rambutan & 13 \\
\hline 21. & Delima & 1 & 65. & Randu & 7 \\
\hline 22. & Durian & 7 & 66. & Red pineapple & 0 \\
\hline 23. & Duwet & 4 & 67. & Sansivera & 45 \\
\hline 24. & Flamboyant & 11 & 68. & Sawo ijo & 4 \\
\hline 25. & Glodokan & 5 & 69. & Sawo kecik & 60 \\
\hline 26. & Heligonia & 30 & 70. & Senu & 2 \\
\hline 27. & Jambu biji & 5 & 71. & Serut jawa & 5 \\
\hline 28. & Jambu dersono /jambu jama & 3 & 72. & Cemara papua & 5 \\
\hline 29. & Jambu mete & 4 & 73. & Singkong karet & 1 \\
\hline 30. & Jarak puter & 2 & 74. & Sono keeling & 19 \\
\hline 31. & Jati & 229 & 75. & Srikaya & 2 \\
\hline 32. & Jemani & 4 & 76. & Sukun & 3 \\
\hline 33. & Kamboja & 9 & 77. & Tabe buaya & 4 \\
\hline 34. & Kantil & 2 & 78. & Tales & 120 \\
\hline 35. & Karet & 5 & 79. & Talok & 48 \\
\hline 36. & Kayu putih & 75 & 80. & Trembalo & 1 \\
\hline 37. & Kelapa & 7 & 81. & Trembesi & 46 \\
\hline 38. & Kelapa sawit & 14 & 82. & Waru & 29 \\
\hline 39. & Kemuning & 1 & 83. & Wuni & 1 \\
\hline 40. & Kanari & 3 & 84. & Salam & 2 \\
\hline 41. & Kepel & 23 & 85. & Angsana & 22 \\
\hline 42. & Ketapang & 11 & \multirow{3}{*}{\multicolumn{2}{|c|}{ Jumlah Total }} & \multirow{3}{*}{2.409} \\
\hline 43. & Klerek & 2 & & & \\
\hline 44. & Kunta bima & 2 & & & \\
\hline
\end{tabular}


Tabel 6. Data Hardscape Taman Balekambang, 2014

\begin{tabular}{|c|c|c|}
\hline No. & Jenis Material & Ukuran \\
\hline 1. & Perkerasan & Lebar 5m \\
\hline 2. & Batu & \\
\hline 3. & Jalan setapak & Lebar $2 \mathrm{~m}$ \\
\hline 4. & Air dan kolam & \\
\hline 5. & Bangunan gedung & \\
\hline 6. & Bangku taman & Luas $4 \mathrm{~m}^{2}$ \\
\hline 7. & Lampu taman & \\
\hline 8. & Pagar/benteng & \\
\hline 9. & Gazebo & Luas $4 \mathrm{~m}^{2}$ \\
\hline
\end{tabular}

Sumber : survey 2013

Tabel 7. Analisis Ketepatan Softscape Taman Balekambang, Solo

\begin{tabular}{|c|c|c|c|c|}
\hline \multirow[b]{2}{*}{ No. } & \multirow[b]{2}{*}{ Kategori } & \multirow[b]{2}{*}{ Standar Softscape } & \multicolumn{2}{|c|}{ Hasil } \\
\hline & & & $\stackrel{\pi}{\nu}$ & $\begin{array}{l}\text { 증 } \\
\stackrel{\underline{O}}{\vdash}\end{array}$ \\
\hline \multirow[t]{5}{*}{1.} & \multirow{5}{*}{$\begin{array}{l}\text { Berdasarkan } \\
\text { Aspek } \\
\text { Arsitektural } \\
\text { dan Artistik } \\
\text { Visual }\end{array}$} & a. Pengontrol pemandangan (visual control) & $\sqrt{ }$ & \\
\hline & & b. Penghalang secara fisik (physical bariers) & $\sqrt{ }$ & \\
\hline & & c. Pengontrol iklim (climate control) & $\sqrt{ }$ & \\
\hline & & d. Pelindung dari erosi (erotion control) & $\sqrt{ }$ & \\
\hline & & e. Memberikan nilai estetika (aesthetics values) & $\sqrt{ }$ & \\
\hline \multirow[t]{6}{*}{2.} & \multirow{6}{*}{$\begin{array}{l}\text { Berdasarkan } \\
\text { Bentuk Tajuk } \\
\text { dan Struktur } \\
\text { Tanaman }\end{array}$} & $\begin{array}{l}\text { a. Tajuk merupakan keseluruhan bentuk dan kelebaran maksimal tertentu dari } \\
\text { ranting dan daun suatu tanaman. }\end{array}$ & $\sqrt{ }$ & \\
\hline & & b. Struktur tanaman ialah bentuk tanaman yang terlihat secara keseluruhan. & $\sqrt{ }$ & \\
\hline & & $\begin{array}{l}\text { c. Tanaman pohon berjenis tanaman berkayu yang biasanya mempunyai batang } \\
\text { tunggal dan dicirikan dengan pertumbuhan yang sangat tinggi, lebih dari } 8 \mathrm{~m} \text {. }\end{array}$ & $\sqrt{ }$ & \\
\hline & & $\begin{array}{l}\text { d. Tanaman perdu adalah tanaman berkayu yang pendek dengan batang yang } \\
\text { cukup kaku dan kuat untuk menopang bagian-bagian tanaman, biasanya dibagi } \\
\text { menjadi tiga, yaitu perdu rendah, perdu sedang, dan perdu tinggi. } \\
\text { e. Tanaman semak (shrubs) dicirikan dengan batang yang berukuran sama dan } \\
\text { sederajat. Pada umumnya tanaman ini mempunyai ketinggian di bawah } 8 \mathrm{~m} \text {. }\end{array}$ & $\sqrt{ }$ & \\
\hline & & $\begin{array}{l}\text { f. Tanaman merambat (liana) lebih banyak digunakan untuk tanaman rambat dan } \\
\text { tanaman gantung. Liana dicirikan dengan batang yang tidak berkayu dan tidak } \\
\text { cukup kuat untuk menopang bagian tanaman lainnya. }\end{array}$ & $\sqrt{ }$ & \\
\hline & & $\begin{array}{l}\text { g. Tanaman Herba, Terna, Bryoids dan Sukulen golongan herba (herbaceous) } \\
\text { atau terna merupakan jenis tanaman dengan sedikit jaringan sekunder atau tidak } \\
\text { sama sekali (tidak berkayu) tetapi dapat berdiri tegak. Ukurannya dibagi } \\
\text { berdasarkan tinggi vegetasi. }\end{array}$ & $\sqrt{ }$ & \\
\hline 3. & $\begin{array}{l}\text { Berdasarkan } \\
\text { Pembentuk dan } \\
\text { Ornamental } \\
\text { Space }\end{array}$ & $\begin{array}{l}\text { a. Tanaman yang membentuk dinding rendah, yaitu tanaman setinggi mata kaki } \\
\text { sampai setinggi lutut. } \\
\text { b. Tanaman yang membentuk dinding sedang, yaitu tanaman yang setinggi lutut } \\
\text { sampai setinggi badan seperti semak yang sudah besar dan perdu. } \\
\text { c. Tanaman yang membentuk dinding tinggi, yaitu tanaman yang setinggi badan } \\
\text { sampai beberapa meter. } \\
\text { d. Tanaman pembatas, pengarah dan pembentuk pandangan adalah jenis } \\
\text { tanaman berbentuk pohon atau perdu yang berfungsi sebagai pembatas } \\
\text { pemandangan yang kurang baik, pengarah gerakan bagi pemakai jalan menuju } \\
\text { ke suatu tujuan tertentu. } \\
\text { e. Tanaman pengarah, penahan dan pemecah angin adalah jenis tanaman yang } \\
\text { berfungsi sebagai pengarah, penahan dan pemecah angin, dapat berbentuk } \\
\text { pohon atau perdu. } \\
\text { f. Tanaman pengatap atau peneduh adalah jenis tanaman berbentuk pohon } \\
\text { dengan percabangan yang tingginya lebih dari } 2 \text { meter. } \\
\text { g. Tanaman sebagai ornamen dan pengisi ruang tanaman yang mempunyai } \\
\text { warna menarik pada bunga, daun, kulit batang atau dahan, serta yang bertajuk } \\
\text { indah. }\end{array}$ & $\begin{array}{l}\sqrt{ } \\
\sqrt{ } \\
\sqrt{ } \\
\sqrt{ }\end{array}$ & \\
\hline
\end{tabular}

Sumber : Analisis 2013 
Tabel 8. Analisis Ketepatan Hardscape Taman Balekambang, Solo

\begin{tabular}{|c|c|c|c|c|}
\hline \multirow[t]{2}{*}{ No. } & \multirow[t]{2}{*}{ Kategori } & \multirow[t]{2}{*}{ Standar Hardscape } & \multicolumn{2}{|c|}{ Hasil } \\
\hline & & & ๘ & \\
\hline 1. & Batuan & $\begin{array}{l}\text { Batuan tidak baik bila diletakkan di tengah taman, sebaiknya di letakkan agak } \\
\text { menepi atau pada salah satu sudut taman. Sebagian batu yang terpendam di } \\
\text { dalam tanah akan memberi kesan alami dan terlihat menyatu dengan taman } \\
\text { akan terlihat lebih indah bila ada penambahan koloni taman pada sela-sela } \\
\text { bebatuan. }\end{array}$ & $\sqrt{ }$ & \\
\hline 2. & $\begin{array}{l}\text { Gazebo dan } \\
\text { Kursi Taman }\end{array}$ & $\begin{array}{l}\text { Bangunan peneduh atau rumah kecil di taman yang berfungsi sebagai tempat } \\
\text { beristirahat untuk menikmati taman. } \\
\text { Bangku taman adalah bangku panjang yang disatukan dengan tempat duduknya } \\
\text { dan di tempatkan di gazebo atau tempat-tempat teduh untuk beristirahat sambil } \\
\text { menikmati taman. }\end{array}$ & $\sqrt{ }$ & $\sqrt{ }$ \\
\hline 3. & $\begin{array}{l}\text { Kolam } \\
\text { dan Air }\end{array}$ & $\begin{array}{l}\text { Dibuat dalam rangka menunjang fungsi gedung atau merupakan bagian taman } \\
\text { yang memiliki estetika sendiri. Kolam sering dipadukan dengan bangunan tebing } \\
\text { dengan permainan air yang menambah kesan dinamis. Kolam akan tampil hidup } \\
\text { bila ada permainan air di dalamnya. }\end{array}$ & $\sqrt{ }$ & \\
\hline 4. & Tebing Buatan & $\begin{array}{l}\text { Tebing buatan atau artificial banyak diminati oleh penggemar taman. Tebing ini } \\
\text { dibuat untuk memberikan kesan alami, tebing dibuat dengan maksud untuk } \\
\text { menyembunyikan tembok pembatas dinding yang licin massif, agar tidak } \\
\text { menyilaukan pada saat matahari bersinar sepanjang siang. }\end{array}$ & & $\sqrt{ }$ \\
\hline 5. & Jalan Setapak & $\begin{array}{l}\text { Jalan setapak atau stepping stone dibuat agar dalam pemeliharaan taman tidak } \\
\text { merusak rumput dan tanaman, selain itu jalan setapak berfungsi sebagai unsure } \\
\text { variasi elemen penunjang taman. }\end{array}$ & & $\sqrt{ }$ \\
\hline 6. & Perkerasan & $\begin{array}{l}\text { Perkerasan pada taman dapat dilakukan dengan menggunakan berbagai macam } \\
\text { bahan, seperti tegel, paving, aspal, batu bata, dan bahan lainnya. Tujuan } \\
\text { perkerasan adalah untuk para pejalan kaki (pedestrian) atau sebagai pembatas }\end{array}$ & $\sqrt{ }$ & \\
\hline 7. & Lampu Taman & $\begin{array}{l}\text { Merupakan elemen utama sebuah taman dan di pergunakan untuk menunjang } \\
\text { suasana di malam hari. Lampu berfungsi penerang taman dan sebagai nilai } \\
\text { artestik tanam. }\end{array}$ & $\sqrt{ }$ & \\
\hline 8. & $\begin{array}{l}\text { Pagar atau } \\
\text { Benteng }\end{array}$ & $\begin{array}{l}\text { Ketinggian maksimal } 1,2 \mathrm{~m} \text { bidang tembus pandang sebesar } 60 \% \text {, bidang masif } \\
\text { setinggi } 0,5 \mathrm{~m} \text { dari permukaan halaman. } \\
\text { Pemerataan ketinggian untuk mencapai pola yang ritmis. } \\
\text { Bidang tembus pandang sebagai aplikasi terhadap control lingkungan, ketertiban } \\
\text { penghuni dan sifat keterbukaan, keramahan terhadap lingkungan. }\end{array}$ & $\begin{array}{l}\sqrt{ } \\
\sqrt{ }\end{array}$ & \\
\hline 9. & Pergola & $\begin{array}{l}\text { Pergola adalah rangka-rangka yang dibuat untuk menyangga dan merambatkan } \\
\text { tanman yang dengan kerapatannya mampu memberikan keteduhan } \\
\text { dibawahnya yang menggantikan fungsi gazebo. }\end{array}$ & $\sqrt{ }$ & \\
\hline 10. & $\begin{array}{l}\text { Bangunan } \\
\text { Gedung }\end{array}$ & $\begin{array}{l}\text { Antara bangunan dan ruang luar-nya harus merupakan satu kesatuan } \\
\text { penampilan. } \\
\text { Pemahaman nilai-nilai bentuk dan garis pada bangunan untuk } \\
\text { menyelaraskannya dengan penampilan lansekap. } \\
\text { Pemahaman bagian-bagian bangunan dalam hubungannya dengan lansekap, } \\
\text { karena lansekap memang melengkapi fungsi dan estetika bangunan sehingga } \\
\text { bagus dipandang baik dari luar maupun dari dalam bangunan. } \\
\text { Memanfaatkan bagian bangunan dalam penampilan lansekap sehingga benar- } \\
\text { benar tidak ada pemisahan antara bangunan dan ruang luar. }\end{array}$ & $\begin{array}{l}\sqrt{ } \\
\sqrt{ }\end{array}$ & \\
\hline
\end{tabular}
Sumber : Analisis 2013

Berdasarkan tabel hasil observasi dan analisisnya di atas, untuk elemen hardscape pada Taman Balekambang belum memenuhi standar, baik terkait kuantitas maupun kualitasnya. Kelengkapan infrasutruktur sebagai syarat taman yang dibutuhkan masih kurang. Sementara itu, dari pihak pengguna maupun pengelola, juga masih terjadi kekurangan perhatian, sehingga kerusakan yang ada semakin mengurangi fungsi dari elemen tersebut. Selanjutnya, untuk elemen softscape, maka tolok ukur RTH yang ada sudah mampu terpenuhi. Sementara itu, berdasarkan karakteristiknya, elelem softscape yang ada didominasi oleh 3 jenis pohon, yaitu pohon berdaun indah $(38,1 \%)$, pohon berbuah $(35,7 \%)$ dan pohon peneduh $(32,2 \%)$. Sementara itu, untuk jenis pohon paling sedikit adalah pohon beraroma, pohon perdu berbunga indah dan pohon 
rambat, yang masing-masing mempunyai persentase $2,4 \%$. Untuk lebih memperjelas tentang jenis dan persentase jenis pohon yang ada, maka berikut ini disajikan dalam bentuk tabel:

Tabel 2. Persentase Elemen Softscape Taman Balekambang, 2014

\begin{tabular}{|r|l|c|}
\hline No & \multicolumn{1}{|c|}{ Jenis Pohon } & $\begin{array}{c}\text { Persen } \\
\text { tase }\end{array}$ \\
\hline 1. & Pohon tajuk indah & $16,7 \%$ \\
\hline 2. & Pohon semak berdaun indah & $16,7 \%$ \\
\hline 3. & Pohon berbuah & $35,7 \%$ \\
\hline 4. & Pohon beraroma & $2,4 \%$ \\
\hline 5. & Pohon berbunga indah & $5,6 \%$ \\
\hline 6. & Pohon berdaun indah & $38,1 \%$ \\
\hline 7. & Pohon peneduh & $32,2 \%$ \\
\hline 8. & Pohon perdu bunga indah & $2,4 \%$ \\
\hline 9. & Pohon rambat & $2,4 \%$ \\
\hline 10. & Pohon semak berbunga indah & $5,6 \%$ \\
\hline
\end{tabular}

Sumber: Disbudpar, 2013

\section{KESIMPULAN DAN SARAN}

Riset ini menyimpulkan bahwa kondisi di Taman Balekambang sebagian besar elemen softscape yang ada sudah memenuhi standar peraturan yang telah ditetapkan sebagai RTH Taman atau Hutan Kota. Namun demikian, dari segi elemen hardscape, baik secara kualitas maupun kuantitas, baik penataan maupun perawatan kurang memadai, sehingga taman terkesan tidak tertata dengan baik. Oleh karena itu, riset ini memberikan saran berupa penyempurnaan elemen hardscape dan pemeliharaan elemen softscape. Selain itu, penataan dan perawatan Taman Balekambang tidak difokuskan di bagian timur saja, tetapi juga bagian barat, supaya kualitas lansekapnya bisa merata.

\section{DAFTAR PUSTAKA}

Arifin, Hadi Susilo, 2006. Penjagaan Tanaman Hiasan Agar Tampil Menawan, Synergi Media, Jakarta.

Ashihara, Yoshinobu, 1996. Perancangan Eksterior dalam Arsitektur, Penerbit Abdi Widya, Bandung.

Disbudpar Surakarta, 2013. Daftar Nama Pohon Taman Balekambang, Dinas Kebudayaan dan Pariwisata UPTD Kawasan Wisata, Surakarta.

DPU, 2008. Peraturan Menteri Pekerjaan Umum No: 05/PRT/M/2008 tentang Pedoman Penyediaan dan Pemanfaatan Ruang Terbuka Hijau di Kawasan Perkotaan, Sekretariat Negara, Jakarta.

Hakim, Rustam, 1991. Arsitektur Lansekap, Manusia, Alam dan Lingkungan, Penerbit Universiras Trisakti, Jakarta.

Handayani, Sri, 2009. Arsitektur Lansekap, Modul Kuliah Arsitektur UPI, Jakarta.

Indrawati, 2007. Ruang Terbuka Hijau, Modul Kuliah Arsitektur UMS, Surakarta.

Sajid, 1984. Babad Sala, Rekso Pustaka, Sala. 